\title{
Price Volatility of Grains: Relationship with Crude Oil Price Using CCC-Multivariate GARCH Model
}

\author{
${ }^{1}$ Areerat Todsadee, ${ }^{2}$ Hiroshi Kameyama and ${ }^{3}$ Shoichi Ito \\ ${ }^{1}$ Prince of Songkla University, SuratThani, Thailand \\ ${ }^{2}$ Department of Applied Bioresource, Faculty of Agriculture, Kagawa University, Kagawa, Japan \\ ${ }^{3}$ Faculty of Agriculture, Kyushu University, Fukuoka, Japan
}

Article history

Received: 2014-12-05

Revised: 2014-12-16

Accepted: 2014-12-27

Corresponding Author: Hiroshi Kameyama Department of Applied Bioresource, Faculty of Agriculture, Kagawa University, Miki-Cho, Kagawa, 761-0795, Japan Email: kameyama@ag.kagawa-u.ac.jp

\begin{abstract}
Agricultural commodities prices have increased and become significantly more volatile during the past few years periods. The high agricultural commodity prices in recent years have raised the question of whether or not volatility is increasing and leading to more frequent extreme price swings. It is very important to quantify price variability of agricultural products. This paper measures the volatility of food commodity prices using multivariate GARCH. Lagged conditional variance and lagged square distribute have an important on the conditional variance. Moreover, the coefficient of the lagged squared effect was positive and statistically significant for feed crop market. We conclude that strong GARCH effects were apparent for agricultural market.
\end{abstract}

Keywords: Agricultural Commodities, Price, Volatility, Multivariate GARCH, Crude Oil

\section{Introduction}

Agricultural commodities prices have increased and become significantly more volatile during the past few years periods. According to OECD (2011), global food markets have undergone a period of marked and persistent volatility. Market instability has been especially intensive since 2006, when inflation in food prices was relevant and led to unprecedented highs between 2006 and 2008. While in the second half of 2008 prices declined again, market turbulences returned in 2010 and 2011. Moreover, the high agricultural commodity prices in recent years have raised the question of whether or not volatility is increasing and leading to more frequent extreme price swings. It is very important to quantify price variability of agricultural products. Another reason for the important of measuring price volatility is the fact that negative price shocks have a greater negative impact on the economic growth. In addition, agricultural price volatility not only affects the usually risk-averse producers and consumers in developed countries, but also undermines food security in poor nations where households spend a substantial portion of their income on food. Particularly rice, corn, wheat and soybean represent the most relevant source of world's food energy consumption, being key to food security (Wright, 2011).
In this study, we focus on assessing volatility in the United States (US) agricultural market including rice, wheat corn and soybean. We focus on this market for two reasons. First, U.S. is the major world producer and exporter of corn. US corn production represents $41 \%$ of global corn output, while US corn exports represent around $54 \%$ of total world exports (in 2010 production was in the order of 333 million metric tons, while exports were almost 50 million metric tons) (USDANASS, 2010). US Soybeans rank second in, after corn, among the most-planted field crops in the U.S. Soybeans is making the U.S. the largest producer and exporter of soybeans, accounting for over $50 \%$ of the world's soybean production and \$3-4 billion in soybean and product exports in the late 2000s. While wheat produces about $10 \%$ of the worlds and supplies about $25 \%$ of the world's wheat export market, however, rice production accounts $2 \%$ of the world's total. Second, it is interesting to study the US agricultural industry due to the important changes it has recently undergone, mainly related to the outburst of the biofuels industry involving an important shift in the demand for agriculture. Agricultural prices have been affected by energy (oil) prices through production and transportation costs, the increased demand for agricultural produce in the production of ethanol has raised concerns about a stronger relationship between energy and agricultural markets and the likely impact of increasing fuel prices on food price volatility. Therefore, 
understanding the source of price volatility and seeking ways to avoid or negative through it is important in ensuring food security and stability (Wright, 2013).

Concern over the degree of commodity price fluctuations or volatility has attracted increasing attention in recent economic and financial analysis (Engle, 1982). Several models solved the problem of dynamic nature of the market which called linear and Non-linear volatility model. The most popular non-linear models financial models are the Autoregressive Conditional Heteroscedastic (ARCH) models or Generalized Autoregressive Conditional Heteroscedastic (GARCH) models (Abd El Aal, 2011).

After food prices are getting popular positions in the portfolio of fund managers of food futures and option, it appears worthwhile to devote effort to modeling food prices with extended GARCH models particularly MGARCH models in the context of world and some countries of Asia and Pacific as well.

The main objective of this study is to study volatility models. The propose volatility models have been modified the GARCH model which is used to evaluate the volatility behavior of agricultural commodity.

\section{Methodology}

\section{Data}

The data consists of daily price of agricultural commodities, rice, corn, wheat, soy bean and crude oil obtained from U.S.A market. The data was downloading from online future trading. The sample is observations from 2nd July 2007 to 7 May 2013. The sample period was chosen according to availability of agriculture prices and this period raised the high price. The characteristic of the data and their descriptive statistics partly indicates appropriate models which should be performed.

Figure 1 illustrates the daily agricultural commodities from 2nd July 2007 to 7 May 2013.This figure presents the plot of daily agricultural prices, rice, corn, soybean, wheat and crude oil. The degree of price between crude oil prices and the prices of rice, corn, wheat and soybean was expected to be higher in 2007-2008 than 2009-2010. During period 2011-2013 all prices, crude oil prices and the prices of rice, corn, wheat and soybean were higher than 2009-2010.

\section{Model}

This study will attempt to model the volatility of daily commodity price using ARCH effect, GARCH and Multiple GARCH models over the entire sample of daily data from 2007-2013.

First, we test Auto Regressive Conditional Heteroskedasticity or ARCH effects by using Engle's Lagrange-multiplier test (1982). The presence of ARCH effect (whether or not volatility varies over time) has to be tested in the conditional variance of:

$$
\begin{aligned}
& \mathrm{h}_{2}=\operatorname{Var}\left(\mathrm{u}_{\mathrm{t}} / \Omega_{\mathrm{t}-1}\right) \\
& h_{2}=\rho_{0}+\rho_{1} u_{t-1}^{t}+\rho_{2} u_{t-2}^{2}+\ldots+\rho_{q} u_{t-q}^{2}
\end{aligned}
$$

where, $u_{t}^{2}$ is the squared residual in period $\mathrm{t}$ and $\rho_{0}, \rho_{1}$, $\rho_{2}, \rho_{\mathrm{q}}$ are the parameters to be estimated.

Second, Generalized Auto Regressive Conditional Heteroskedasticity (GARCH) model is employed to do. The GARCH is popular volatility model, introduced by Bollerslev (1986). We start by defining the daily log return of agricultural prices as the change of the logarithm of the daily closing of prices. The daily log price can be written as:

$y_{t}=\ln \left(P_{t+1}\right)-\ln \left(P_{t}\right)$

A discrete-time log daily price is assumed for this paper, giving the form of mean equation and the error term process as following:

$\mathrm{y}_{\mathrm{t}}=\mu+\varepsilon_{\mathrm{t}}$

$\mu=\mathrm{y}_{\mathrm{t}}-\varepsilon_{t}$

where, the error term is a function of the log daily price and unconditional mean. These equations are the starting equations for the following assumptions.

As financial asset returns evolve, they tend to move together. Their respective volatilities also tend to move together over time, acre both assets and marketing. The Multivariate Condition Volatility Models or MGARCH model stands for multivariate GARCH. Consider the CCC multivariate GARCH model of Bollerslev (1990) can be written as:

$y_{2}=E\left(\left(y_{t} \mid F_{t-1}\right)+\varepsilon_{t}, \varepsilon_{t}=D_{t} \eta_{t} \operatorname{var}\left(t \mid F_{t-1}\right)=D_{t} \Gamma D_{t}\right.$

where, $\mathrm{y}_{\mathrm{t}}=\left(\mathrm{y}_{1 \mathrm{t}}, \ldots, \mathrm{y}_{\mathrm{mt}}\right)^{\prime}, \eta_{\mathrm{t}}=\left(\eta_{1 \mathrm{t}}, \ldots, \eta_{\mathrm{mt}}\right)^{\prime}$ is a sequence of independently and identically distribute (i.i.d.) random vectors, $F_{t}$ is the past information available at time $\mathrm{t}, \mathrm{D}_{\mathrm{t}}=\operatorname{diag}\left(h_{1}^{1 / 2}, \ldots, h_{m}^{1 / 2}\right), \mathrm{m}$ is the number of returns and $\mathrm{t}=1, \ldots, \mathrm{n}$. As $\Gamma=\mathrm{E}\left(\eta_{t} \eta_{t}^{\prime} \mid F_{t-1}\right)=E\left(\eta_{t} \eta^{\prime}\right)$, where $\Gamma=\left\{\rho_{i j}\right\}$ for $\mathrm{i}, \mathrm{j}=1, \ldots, \mathrm{m}$, the constant covariance matrix of the unconditional shocks, $\eta t$, is equivalent to the constant conditional covariance matrix of the conditional shocks, t, from (6), $t t=D_{t} \eta_{t} \eta_{t}^{\prime} D_{t}, D_{t}=\left(\operatorname{diag} Q_{t}\right)^{1 / 2}$ and $E\left(t t \mid F_{t-1}\right)=Q_{t}=D_{t} \Gamma D_{t}$, where $\mathrm{Q}_{\mathrm{t}}$ is the conditional covariance matrix.

The CCC model of Bollerslev (1990) assumes that the conditional variance for each return, $h_{i t}, i=1, \ldots, m$, following a univariate $\mathrm{GARCH}$ process, that is: 


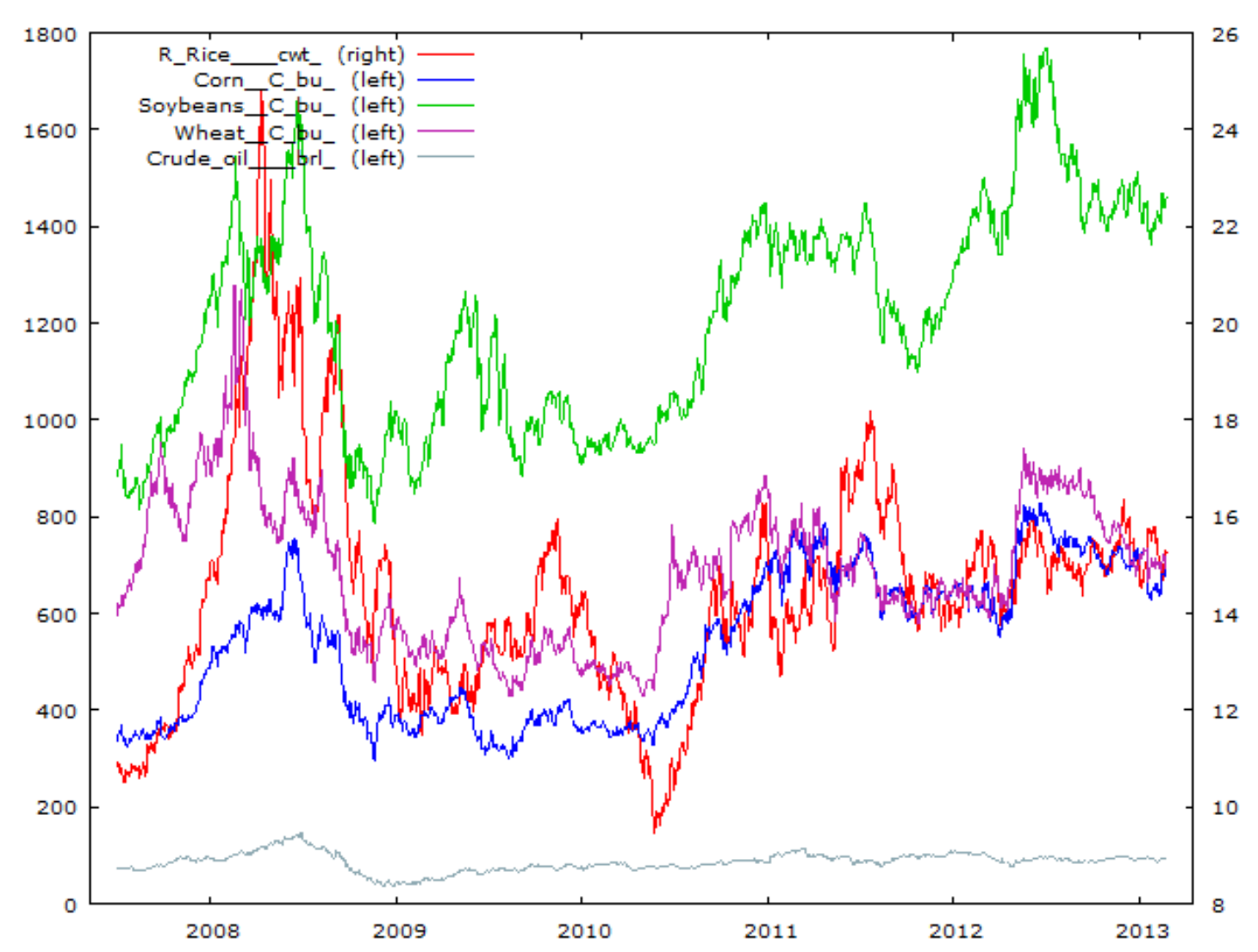

Fig. 1. Daily price of Rice, Milled rice, Corn, Soybeans and Crude oil from 2007-2013

Table 1. ARCH-LM test

\begin{tabular}{lcl}
\hline Variables & F-statistic & Probability \\
\hline Rice (ARCH 1) & 8.173 & $0.0043^{*}$ \\
Corn (ARCH 1) & 7.593 & $0.0059^{*}$ \\
Soybean (ARCH 1) & 11.800 & $0.0006^{* *}$ \\
Wheat (ARCH 1) & 126.466 & $0.0000^{* * *}$ \\
Crude oil (ARCH 1) & 12.945 & $0.0003^{* *}$ \\
\hline
\end{tabular}

Source: Arthur calculation

Note: $* * *, * * *$ is reject null hypothesis of no ARCH effect at 1,5 and $10 \%$ level

Table 2. The GARCH estimation

\begin{tabular}{|c|c|c|c|c|c|}
\hline $\operatorname{GARCH}(1,1)$ & Rice & Corn & Soybean & Wheat & Crude oil \\
\hline Intercept $\omega$ & $0.00304 * * *(0.0086)$ & $2.2271 *(1.129)$ & $8.229 *(4.226)$ & $27.33 * *(11.878)$ & $0.0468(0.0381)$ \\
\hline $\mathrm{ARCH} \alpha$ & $0.2173 * * *(0.0457)$ & $0.0554 *(0.022)$ & $0.0781 * * *(0.0175)$ & $0.154 * * *(0.0378)$ & $0.1100 * * *(0.0254)$ \\
\hline GARCH $\beta$ & $0.76399 * * *(0.0465)$ & $0.9258 * * *(0.029)$ & $0.9108 * * *(0.020)$ & $0.7879 * * *(0.050)$ & $0.8883 * * *(0.0257)$ \\
\hline$\alpha+\beta$ & 0.98129 & 0.9812 & 0.9889 & 0.9427 & 0.99833 \\
\hline Log-likelihood & -115.712 & -1909.93 & -2311.75 & -2228.68 & -1141.43 \\
\hline
\end{tabular}

Source: Arthur's calculation

Note: $* * *$ indicate significant at $1 \%$ level, $* *$ indicate significant at $5 \%$ level

Table 3. Constant conditional correlation for CCC-MGARCH estimation

\begin{tabular}{llllll}
\hline & Rice & Corn & Soybean & Wheat & Crude oil \\
\hline Intercept $(\omega)$ & $0.00410 * *(0.0015)$ & $5.524(3.018)$ & $15.979 * *(6.825)$ & $30.223 * *(12.36)$ \\
ARCH $(\alpha)$ & $0.230 * * *(0.230)$ & $0.069 *(0.031)$ & $0.0842 * * *(0.023)$ & $0.174 * * *(0.04)$ \\
GARCH $(\beta)$ & $0.7367 * * *(0.067)$ & $0.8825 * * *(0.053)$ & $0.890 * * *(0.029)$ & $0.7665 * * *(0.053)$ \\
$\alpha+\beta$ & 0.966 & 0.951 & 0.974 & 0.94 & $0.116 * * *(0.033)$ \\
\hline
\end{tabular}

Source: Arthur's calculation

Note: $* * *, * * *$ is significant at 1,5 and $10 \%$ level 
Table 4. Constant conditional correlation for CCC-MGARCH

\begin{tabular}{lllll}
\hline & Corn & Soybean & Wheat & Crude oil \\
\hline Rice & $0.3745^{* * *}(0.039)$ & $0.299^{* * *}(0.0416)$ & $0.4043^{* * *}(0.0380)$ & $0.3553^{* * *}(0.0401)$ \\
Corn & & $0.678^{* * *}(0.024)$ & $0.58366^{* * *}(0.030)$ & $0.4776^{* * *}(0.035)$ \\
Soybean & & & $0.532^{* * *}(0.0327)$ & $0.531^{* * *}(0.039)$ \\
Wheat & & & $0.363^{* * * *}(0.399)$ \\
\hline
\end{tabular}

Source: Author calculation

Note: $* * *$ is significant at $1 \%$ level

$$
h_{i t}=\omega_{i}+\sum_{j=1}^{r} \alpha_{i j i, t-j}^{2}+\sum_{j=1}^{s} \beta_{i j} h_{i, t-j}
$$

where, $\alpha_{i j}$ represents the ARCH effect, or short run persistence of shocks to return $\mathrm{i}, \beta_{\mathrm{ij}}$ represents the GARCH effect and $\sum_{j=1}^{r} \alpha_{i j}+\sum_{j=1}^{s} \beta_{i j}$ denotes the long run persistence.

\section{Empirical Results}

\section{ARCH Estimation of Crops Price Volatility}

The tests for conditional heteroskedasticity which is Lagrange Multiplier teat is carried out in this study. The test can be thought of as a test for auto correction in the squared residuals where the null hypothesis is that all $\mathrm{q}$ lags of the squared residual have values equal to zero. The rejection of null hypothesis indicates the coefficients are significantly differently from zero when fitting $\mathrm{ARCH}$ equations, Lagrange Multiplier (LM) and F-tests were used to test the null hypothesis of no ARCH effect. The results for the ARCH-LM test are presented in Table 1.

As can be seen in Table 3, the test for presence of ARCH effect confirmed the presence of ARCH (1) in all cases. The confirmation of the presence of $\mathrm{ARCH}$ effect in these cases indicates that the volatility in the prices of these crops is time varying and hence it is suggested that the GARCH approach be used instead. In this experiment, we chose all series for testing the agriculture impact on price volatility.

\section{GARCH Estimation}

Table 2 presented the result of GARCH parameters (standard errors in parenthesis) for model fitted to prices of agricultural market. The first coefficients $\omega$ (constant), ARCH term $(\alpha)$ and $\operatorname{GARCH}(\beta)$ of GARCH $(1,1)$ model were statistically significant in all series and exhibit the expected sign, rice, corn, soybean, wheat and crude oil. The significant of $\alpha$ and $\beta$ indicates that, lagged conditional variance and lagged square distribution have an impact on the conditional variance, in other words this means that news about volatility from the previous period have an explanatory power on current volatility.

Moreover the magnitudes of the coefficients, $\beta$, were especially high for wheat and crude oil, 0.94 and 0.99 respectively; however, the high and low beta estimates exhibit high level of variability. Although low values of ARCH term $(\alpha)$ suggest that large market surprises induce relatively small revision in future volatility forcorn and soybean, 0.055 and 0.0781 respectively.

\section{Multivariate GARCH}

Table 3 presented the result of CCC-MGARCH in agricultural market- corn and soybean meal prices. These results are available upon request. All multivariate condition volatility models in this study are estimated using the Stata 12 econometric software package (Stata Press, 2011). The ARCH and GARCH estimated the conditional variances of commodities prices were statistically significant. The ARCH $(\alpha)$ estimates were generally small (less than 0.2 ) and the GARCH $(\beta)$ estimates were generally high and close to one. Therefore, the long run persistence, was generally close to one indicating a near long memory process. In addition, since $\alpha+\beta<1$, all markets satisfy the second moment and log-moment condition.

For the agricultural markets, there are 5 series of agriculture series to be analyzed. The calculated constant conditional correlations the volatilities of USA market using the CCC model is present in Table 4. The highest estimated constant correlation is 0.678 , namely between the corn series and soybean series. In addition, the smallest correlation between rice and corn is close to zero, 0.299 .

Regarding the correlation between the volatility of crude oil and rice, it can be seen that is positive during the whole sample period but correlation shows large peak is 0.355 . Similar to the correlation between the volatility of crude oil and wheat, the correlation is close to zero, 0.363 . While the correlation between crude oil series and corn series are larger than the rice and crude oil, namely 0.477 or close to 0.5 . However, the correlation between crude oil and soybean shows larger among the agricultural series, rice, corn and wheat. This implies that crude oil and soybean are rise together.

\section{Conclusion}

Agricultural commodities prices have increased and become significantly more volatile during the past few years periods. The high agricultural commodity prices in recent years have raised the question of whether or not volatility is increasing and leading to more frequent extreme price swings. It is very important to quantify price variability of agricultural products. Another reason for the important of measuring price volatility is the fact 
that negative price shocks have a greater negative impact on the economic growth.

We focus on USA market for two reasons. First, U.S. is the major world producer and exporter of corn, wheat, soybean and rice. Second, it is interesting to study the US agricultural industry due to the important changes it has recently undergone, mainly related to the outburst of the biofuels industry involving an important shift in the demand for agriculture. The main objective of this study is to study volatility models. In this study used the Generalized Autoregressive Conditional Heteroscedastic or GARCH models to estimate volatility in the daily agricultural prices of U.S.A. market. The sample size was observations from 2nd July 2007 to 7 May 2013.

From the results, the ARCH term $(\alpha)$ and GARCH $(\beta)$ of GARCH $(1,1)$ model were statistically significant in all series, rice, corn, wheat, soybean and crude oil series. These results indicated that, lagged conditional variance and lagged square distribute have an important on the conditional variance. Moreover, the coefficient of the lagged squared effect was positive and statistically significant for feed crop market. We conclude that strong GARCH effects were apparent for agricultural market. For multivariate GARCH, the sum of $\alpha$ and $\beta(\alpha+\beta)$ were high and close to one, indicates a near long memory process: A shock in the volatility series impacts on futures volatility over a long horizon. The estimated conditional correlation parameters were positive and significant indicates that returns on these stocks rise or fall together for agricultural market. The highest estimated constant correlation is 0.678 , namely between the corn series and soybean series. In addition, the smallest correlation between rice and corn is close to zero, 0.299 .

Looking at volatilities, it is interesting to note that correlations between soybean and crude oil and those between agricultural and energy factor present low values during the 2007-2013 time period.

This study is important to the policy maker to preparing the developing and investment plans. Moreover, the forecasting of volatility is important for the fund manger how selecting the optimal portfolio depending of homoscedastic normal process helps the policy maker, fund manager and academic to choose the optimal model to predicting of financial market return volatility.

\section{Author's Contributions}

All authors equally contributed in this work.

\section{Ethics}

This article is original and contains unpublished material. The corresponding author confirms that all of the other authors have read and approved the manuscript and no ethical issues involved.

\section{References}

Abd El Aal, M.A., 2011.Modeling and forecasting time varying stock return volatility in the Egyptian stock market. Int. Res. J. Finance Econom.

Bollerslev, T., 1986. Generalized autoregressive conditional heteroskedasticity. Econometrics, 31: 307-3327. DOI: 10.1016/0304-4076(86)90063-1

Bollerslev, T., 1990. Modelling the coherence in shortrun nominal exchange rates: A multivariate generalized ARCH model. Rev. Econom. Statist., 72: 498-505. DOI: 10.2307/2109358

Engle, R.F., 1982. Autoregressive conditional heteroscedasticity with estimates of the variance of United Kingdom inflation. Econometrica, 50: 987-1007. DOI: 10.2307/1912773

OECD, 2011. Price volatility in food and agricultural markets: Policy responses. Organisation for Economic Cooperation and Development.

Stata Press, 2011. Stata release 12 data management. Texas, United States.

USDA-NASS, 2010. United States Department of Agriculture-National Agricultural Statistics Service.

Wright, B.D., 2011. The economics of grain price volatility. Applied Econ. Perspectives Policy, 33: 32-58. DOI: 10.1093/aepp/ppq033

Wright, B.D., 2013. GFT-online future trading. 